Document downloaded from:

http://hdl.handle.net/10251/47989

This paper must be cited as:

Curiel Esparza, J.; Cantó Perelló, J. (2013). Selecting utilities placement techniques in urban underground engineering. Archives of Civil and Mechanical Engineering. 13(2):276285. doi:10.1016/j.acme.2013.02.001.

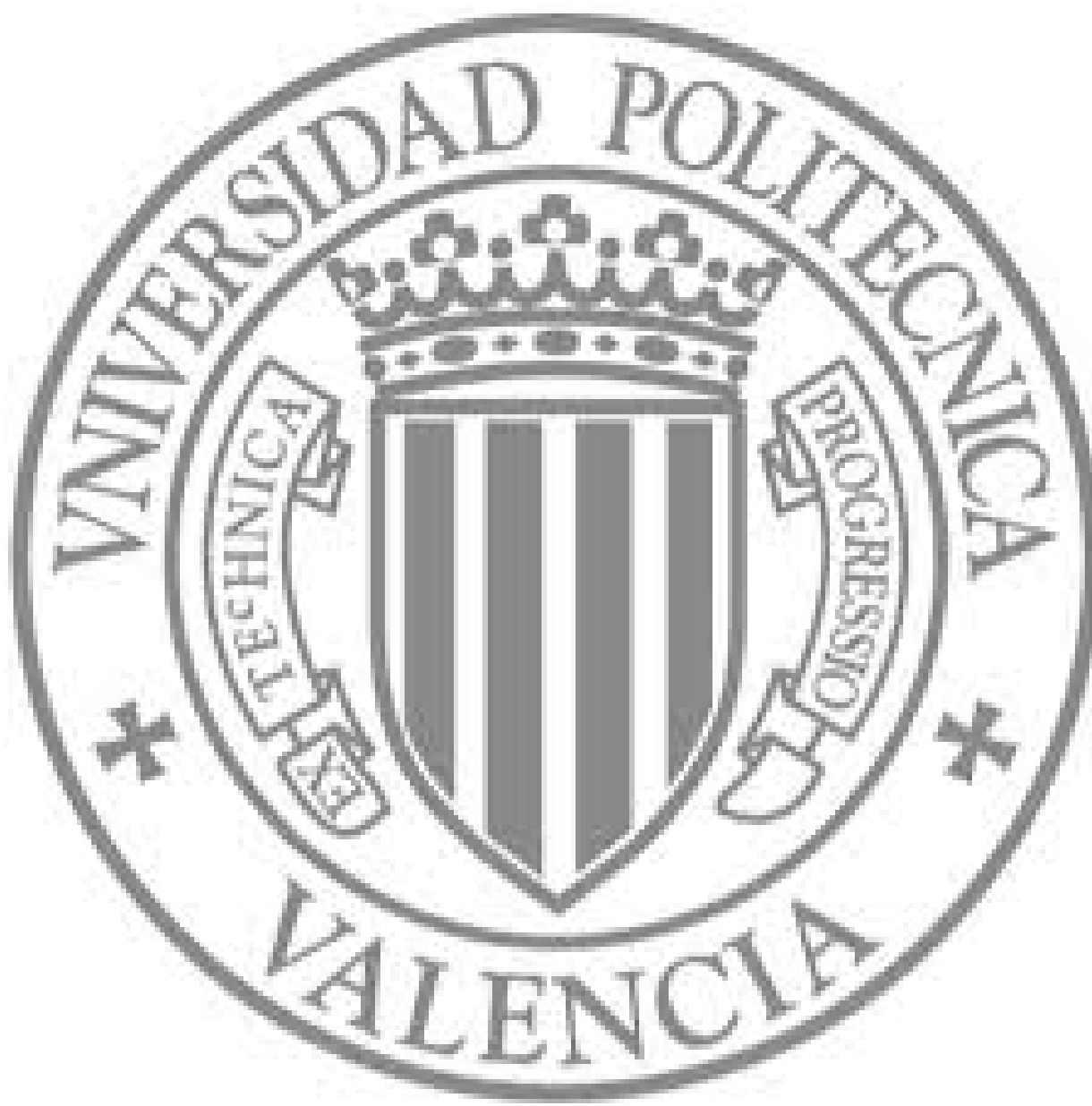

The final publication is available at

http://dx.doi.org/10.1016/j.acme.2013.02.001

Copyright Elsevier 


\title{
Selecting utilities placement techniques in urban underground engineering
}

\section{J. Curiel-Esparza ${ }^{a^{*}}$ and J. Canto-Perello}

${ }^{a}$ Physical Technologies Center, Universitat Politecnica de Valencia, Camino de Vera s/n, 46022 Valencia, Spain

${ }^{\mathrm{b}}$ Department of Construction Engineering and Civil Engineering Projects, Universitat Politecnica de Valencia, Camino de Vera s/n, 46022 Valencia, Spain

*Corresponding author. Tel.: +34 6387 7520; fax: +34 63877529.

E-mail: jcuriel@fis.upv.es

\begin{abstract}
Placement of utilities has not been generally accomplished in any sustainable technique resulting in a veritable maze in high density urban areas. As underground space scarcity grows in our cities due to the increasing demands for utility services, subsurface facilities such as utility tunnels are becoming more efficient in providing the required infrastructure. There is a growing public awareness of aesthetic considerations and impatience with street cuts and their associated costs, traffic interferences, noise and accidental utility cuts. Unfortunately the lack of data and the difficulty in quantifying the intangibles has made it impossible to arrive at a reasonably accurate figure of overall negative impact on the urban environment of street cuts. Due to this, current practices of traditional trenching depending only on cost indicators remain as first option in urban planning instead of more sustainable techniques, like utility tunnels. However, it is well known that intangible costs to the public and the utilities might make the utility tunnel concept to be economically feasible in the long run. This paper presents a methodology based on AHP and Delphi processes for the selection of utilities placement techniques in which the intangibles are also assessed to avoid short-sighted urban underground planning.
\end{abstract}

\section{Highlights}

Quantifying intangibles is a key factor to study negative impact of street cuts. Only use of cost indicators make traditional trenching to remain as first option. Intangible costs might make utility tunnel concept to be feasible in the long term. A methodology based on AHP and Delphi avoids short-sighted underground planning.

\section{Keywords}

Urban utilities; underground space; municipal engineering; AHP Delphi 


\section{Introduction}

The most rapid increase in the use of urban underground space began since the $19^{\text {th }}$ century, due to the impetus of city development. Underground medium provides the setting for utilities that are unsecure or environmentally undesirable to install above ground. But without any doubt, there is an increasing interest on the need for sustainable planning in our cities [1-4]. Moreover, it is part of European Union policy to achieve a high level of health and environmental protection, and one of the objectives to be pursued is sustainable development [5]. In central areas of large towns, with large concentrations of population in a limited area, it has become necessary to utilize the subsurface for locating a growing number of services. This has resulted in a veritable maze of pipes and cables under the streets pavements nicknamed as spaghetti by civil engineers [6-8]. The incessant cutting of pavements to install or repair underground facilities causes traffic delays, poses safety hazards, pollutes the environment, creates aesthetic detriments, reduces the useful life of pavements and limits access to abutting properties. Moreover, when repairing one strand of spaghetti, workers sometimes damage another. To overcome these disadvantages, utility tunnels provide the means to use inventiveness and good engineering practices in developing sustainable and coordinated installations of utility systems essential to tomorrow's urban needs. Tunnelling is increasingly being used world-wide to provide the infrastructure required for sustainable cities [9-13]. Utility tunnels can house the full range of power, communications, water, gas and other distribution systems. They may well constitute the answer to the perennial problem plaguing many municipalities. There is complete agreement that the initial cost of a utility tunnel would be more than that for a traditional trenching installation. However, it should be noted that intangible costs to the public and the utility companies might make the utility tunnel concept more sustainable and economical in the long term. Unfortunately the lack of data and the difficulty in quantifying the intangibles has made it impossible to arrive at a reasonably accurate figure of overall negative impact on the urban environment of street cuts [14-15]. Sustainable development of underground space not just calls for using underground space, but using it to combine functions and to create value in doing so for society [16-23]. Establishing future sustainable strategies in urban underground engineering consists of the ability to lessen the use of traditional trenching [24,25]. This paper presents a methodology for the selection of utilities placement techniques in which the intangibles are also assessed to avoid short-sighted planning.

The Analytic Hierarchy Process is a theory of relative measurement on absolute scales capable of dealing with intangible criteria and based on paired comparison judgement of knowledgeable experts [26-30]. How to measure intangibles is the main concern of the mathematics of the AHP as this paper will show. Although AHP is subject to criticism, it is regarded as the most appropriate method for this study. This method is very suitable for complex social issues in which intangible factors cannot be neglected. The Delphi technique is well suited as a means and method for consensus-building by using a series of questionnaires to collect data from a panel of selected subjects [31-33]. The Delphi technique is performed to facilitate an efficient panel of experts' dynamic process. This is done in the form of an anonymous, written, multistage survey process, where feedback of the group opinion is provided. This paper proposes an AHP-Delphi model to support civil engineers' decisions in urban underground planning. 


\section{First questionnaire and decision hierarchy structure}

It is significant to note that utility tunnel feasibility studies conducted recently found economic justification based solely on tangible factors [34,35]. However the lack of data and the difficulty in quantifying the intangibles must be taken into account in urban planning. The intangibles, like noise and aesthetic considerations, traffic delays and disturbances due to street cuts, long term deterioration of streets are not quantified [36]. Today, we have a new dimension: quantity has made way for quality. People are willing to pay the price for a pleasing landscape. The theme seems to be "don't put it here" or "put it where I can't see it" and this demands a joint cooperative effort. To overcome the lack of tangible data and the use of intangible criteria, AHP-Delphi model will be applied to advance in utilities planning. Integrating the AHP with a Delphi process provides a civil engineer with a systematic approach to evaluate multi-criteria and multi-alternative problems which requires judgements involving intangible characteristics. The Delphi first phase will be exploration of the alternatives and criteria under discussion between experts, using an anonymous questionnaire where each expert contributes with additional alternatives or criteria he feels is pertinent to the goal. The next process is to feedback the collated information and ask them to reconsider their proposals. With this anonymous feedback, experts with different perspectives contribute to each other's understanding of the topics involved and move toward a consensus. Criteria and alternatives that are accorded low importance are removed. An adequate selection of criteria is a key factor for this procedure as will be discussed later on. To understand the process, a brief description of the alternatives and criteria selected follows.

In our case, five possible alternatives for utilities placement in urban subsurface have been addressed. These alternatives are:

1. Traditional trenching, where several utilities are grouped in a multi-layer single trench.

2. Common conduit, where one or more utilities are placed in multiple ducts in a single trench.

3. Flat UT, essentially a non-walk-through utility tunnel with a removable concrete lid, which could be used as street pavement or disposed in a shallow position $(<1 \mathrm{~m})$.

4. Shallow UT, which is a walk-through underground structure $(<5 \mathrm{~m})$ containing one or more utility systems, permitting the installation, maintenance, and removal of the system without making street cuts or excavations.

5. Deep UT, similar to the previous but positioned deeper ( $>5 \mathrm{~m})$.

To achieve the objective of selecting one of these utilities placement techniques several criteria have been proposed: urban environment, economic-financial, governance, maintenance requirements, security, liability and archaeological requirements. Environmental conditions in urban areas are a source of critical concern worldwide. The qualities and attractiveness of the cities are not only determined by the fulfilment of the material economic needs of their citizens, but also by the social and environmental conditions which prevail [37,38]. After installation under streets, utility systems are far from unobtrusive. Their presence is well indicated by the seemingly ceaseless opening of the streets to make repairs and provide new and larger systems and services. These openings, often called street cuts, cause serious delays to traffic, create noise and aesthetic disturbances, and result in excessive street maintenance requirements and in shortened overall street life [39,40]. Utility network owners install, operate, perform maintenance, and repair their network independently by working in the relatively congested underground areas beneath our narrow streets and pavements, which means in turn that different 
utility networks are inevitably too close to each other than is desirable from an engineering viewpoint. This increases the possibility that other utility networks might be damaged when installation, repair or refurbishment work is carried out by any one utility company [41]. Accurate location of buried utilities is a vital issue specially when using trenching techniques [42]. Financial requirements may be defined as the feasibility of obtaining the necessary capital for construction of utility tunnel systems and establishing revenues for the recovery of capital and operating costs. It is not possible to make a general statement as to the engineering-financial feasibility of utility tunnels because each situation will be different in terms of location, urban population and traffic density, utility systems to be installed, type and number of customers, costs of construction and many other factors [43]. In addition, a critical requirement in the development of urban utility tunnel systems is the cooperation and coordination of all government and utility agencies so that a workable plan can be developed [44,45]. Problems relating to the liability and security of a variety of utility systems in close proximity inside a tunnel need to be evaluated for each case by the expert panel [46-51]. Moreover, protecting heritage must in no case be neglected [52,53] and this constraint must be taken into account in the schedule of the utility projects, notably in order to allow for archaeological excavations. In this respect, it should also be recognized that sustainable underground policies, which include utility tunnels, help protect archaeological sites. Taking into account all these requirements and following the initial step of AHP [54], the goal is decomposed into a hierarchy structure shown in Fig. 1. Obviously, the criteria and alternatives to be used by any community will be tailored to local needs.

\section{Second questionnaire and construction of pairwise comparison matrix for the criteria}

According to Delphi process, the second questionnaire which is sent to the panel of experts will be used to assess main criteria. The Delphi process achieves interaction among the panel of experts with anonymous feedback, while AHP is used to divide the overall decision making into smaller decision components. As an example, Table 1 shows a particular questionnaire for evaluating main criteria with respect to the overall goal using 9-point scale (see Table 2). This scale has been validated for effectiveness, not only in many applications by a number of people, but also through theoretical comparisons with a large number of other scales [55]. Each expert performed a pairwise comparison to indicate his preference for each criterion. As a result, a matrix evaluating results of the main criteria with respect to the overall goal is obtained (see Table 3). Pairwise comparison matrix for the criteria is constructed using the mean value obtained from Table 3.

\section{Priority weighting of the criteria and consistency ratio}

After developing the pairwise comparison matrix for the criteria $(A)$, the relative priority of each individual criterion will be determined. The matrix is given by 


$$
A=\left[\begin{array}{ccccccc}
1 & 4.1333 & 7.8000 & 1.2210 & 4.6000 & 6.0000 & 5.4000 \\
0.2419 & 1 & 7.8000 & 0.6552 & 2.0400 & 3.3333 & 3.8000 \\
0.1282 & 0.1282 & 1 & 0.1517 & 0.1613 & 0.2590 & 0.6000 \\
0.8190 & 1.5262 & 6.5900 & 1 & 4.0000 & 5.8000 & 7.8000 \\
0.2174 & 0.4902 & 6.2008 & 0.2500 & 1 & 2.2000 & 3.8000 \\
0.1667 & 0.3000 & 3.8603 & 0.1724 & 0.4545 & 1 & 1.3067 \\
0.1852 & 0.2632 & 1.6667 & 0.1282 & 0.2632 & 0.7653 & 1
\end{array}\right]
$$

The principal eigenvector of $A$ is the desired priority vector $\omega$ according to Saaty [56]. To find this priority vector, the linear system $A \omega=\lambda \omega$ must be solved

$$
\operatorname{det}(A-\lambda I)=0
$$

Hence, the priority vector of the criteria is as follows

$$
\omega=\left[\begin{array}{l}
0.3467 \\
0.1581 \\
0.0253 \\
0.2728 \\
0.1024 \\
0.0549 \\
0.0397
\end{array}\right]
$$

One of AHP's advantages is to measure whether or not inconsistency occurs in the evaluation process. That is, experts are often not able to express consistent preferences in case of several criteria. To address this possibility, the Saaty's method measures the inconsistency of the pairwise comparison matrix and sets a consistency threshold which should not be exceeded in order to guarantee the procedure. The consistency ratio $(C R)$ is used as the main indicator of ranking consistency. In practice, a $C R$ of 0.1 or below is considered acceptable for order of matrix (n) equal or larger than five. Any higher score indicates that the judgements need reexamination. $C R$ is calculated by dividing the consistency index $(C I)$ by the random consistency index $(R C I)$ obtained from Saaty (1980), as follows

$$
C R=\frac{C I}{R C I}
$$

In order to calculate the $C I$, largest eigenvalue $\left(\lambda_{\text {máx }}\right)$ of the normalized pairwise comparison matrix should be determined. Hence, the next step is to normalize the pairwise comparison matrix. This is done by totalling the numbers in each column. Each entry in the column is then divided by the column sum to yield its normalized value. Therefore, the normalized matrix $\left(A_{N}\right)$ is given by 


$$
A_{N}=\left[\begin{array}{lllllll}
0.3625 & 0.5271 & 0.2234 & 0.3412 & 0.3674 & 0.3100 & 0.2278 \\
0.0877 & 0.1275 & 0.2234 & 0.1831 & 0.1630 & 0.1722 & 0.1603 \\
0.0465 & 0.0164 & 0.0286 & 0.0424 & 0.0129 & 0.0134 & 0.0253 \\
0.2969 & 0.1946 & 0.1887 & 0.2794 & 0.3195 & 0.2996 & 0.3290 \\
0.0788 & 0.0625 & 0.1776 & 0.0699 & 0.0799 & 0.1136 & 0.1603 \\
0.0604 & 0.0383 & 0.1106 & 0.0482 & 0.0363 & 0.0517 & 0.0551 \\
0.0671 & 0.0336 & 0.0477 & 0.0358 & 0.0210 & 0.0395 & 0.0422
\end{array}\right]
$$

Then, the consistency index $(C I)$ is calculated as follows

$$
C I=\frac{\lambda_{\text {máx }}-n}{n-1}
$$

The process followed to determine the relative preference rating of the criteria is then completed as shown in Table 4.

\section{Third questionnaire and evaluate alternatives according to criteria}

The next step is to calculate the priority of alternatives with respect to each criterion. The third questionnaire which is sent to the panel of experts will be used to assess alternatives for each criterion. As an example, Table 5 shows a particular questionnaire for evaluating alternatives using Table 2 with respect to an individual criterion (C1-Urban environment) to better illustrate the use of the proposed model. Each expert has performed a pairwise comparison to indicate his preference for each alternative. Then, a pairwise comparison matrix for the alternatives is constructed using the mean value obtained from experts. As in previous steps, eigenvector method has been applied to obtain the priority vector, and consistency analysis performed for each case. All criteria assessments are shown in Table 6 to Table 12.

The last step is to obtain overall priorities. First, a matrix of priority vectors for alternatives is constructed as shown in Table 13. And finally, the overall priority result (see Table 14) is done by matrix multiplication between the matrix of priority vectors for alternatives and the priority vector of the criteria $(\omega)$.

\section{Results and discussions}

Results show that in our example deep and shallow utility tunnels, with an overall priority of $28.78 \%$ and $25.12 \%$ respectively, are preferred solutions for this case (see Table 14). The weights of each alternative for each criterion are illustrated in Fig. 2. However, because Fig. 2 is not considering the prioritization of the criteria, special attention must be given to the fact that this figure seems at first sight to refute misleadingly the use of utility tunnels. This result is not surprising; because criteria C1-Urban Environment and C4-Maintenance requirements have been rated by experts as the most significant factors (see Fig. 3). It is interesting to note, however, that to another community where the criterion C2-Economic-financial is preferred, the result would be different. This methodology is tailored to the needs of each community, and 
therefore the importance given to each criterion in a particular case by the panel of experts is decisive in the selection procedure as pointed previously.

As cities continue to grow, establishing future sustainable strategies in urban underground engineering will require suitable procedures for complex issues in which intangible factors cannot be neglected. This paper has proposed the use of AHP for making decisions in an organised way to generate priorities in urban underground, and the Delphi technique to facilitate an efficient group dynamic process for achieving consensus. The hierarchy of the decision has been constructed based on the panel of experts' suggestions derived by using Delphi procedure. That is, each expert has been asked to identify possible alternatives and criteria that could affect the selection of utilities placement techniques in urban underground through several questionnaires until a consensus has been reached. Once the hierarchy was established, experts' knowledge has been collected through questionnaires to construct a set of pairwise comparison matrices to prioritize criteria and alternatives using AHP technique. Finally, the results obtained will be used to support civil engineers' decisions in selecting utilities placement techniques. In conclusion, the AHP-Delphi model proposed in this paper has been shown as a reliable method in urban underground planning to overcome intangible factors and scarcity of knowledge.

\section{References}

[1] P. Du aut, Paris Conference examines the "Rightful Place" of the underground space in the modern city, Tunnelling and Underground Space Technology 11 (1) (1996) 126-130.

[2] X. Liu, X. Li, B. Ai, H. Tao, S. Wu, T. Liu, Multi-agent systems for simulating and planning land use development, Acta Geographica Sinica 61 (10) (2006) 1101-1112.

[3] S.W. Choon, C. Siwara, J.J. Pereira, A.A. Jemainc, H.S. Hashima, A.S. Hadib, A sustainable city index for Malaysia, International Journal of Sustainable Development \& World Ecology 18 (1) (2011) 28-35.

[4] L. He, Y. Song, S. Dai, K. Durbak, Quantitative research on the capacity of urban underground space - The case of Shanghai, China, Tunnelling and Underground Space Technology 32 (1) (2012) 168-179.

[5] R. Steurera, G. Bergerb, The EU's double-track pursuit of sustainable development in the 2000s: how Lisbon and sustainable development strategies ran past each other, International Journal of Sustainable Development \& World Ecology 18 (2) (2011) 99-108.

[6] W.J. Boegly, W.L. Griffith, Underground utility tunnels, Mechanical Engineering 93 (9) (1971) 27-32.

[7] E.H.J. Oude, Underground space for utilities, in: Proceedings of the International Conference on Underground Space and Earth Sheltered Structures, 1992.

[8] J. Curiel-Esparza, J. Canto-Perello, M.A. Calvo, Establishing sustainable strategies in urban underground engineering, Science and Engineering Ethics 10 (3) (2004) 523-530.

[9] C. Madryas, Service tunnels in newly built residential areas, Tunnelling and Underground Space Technology 5 (4) (1990) 363-366.

[10] V. Hokkanen, I. Forssén, M. Niva, K. Sorjonen, Four examples of subsurface uses in Finland Tunnelling and Underground Space Technology, 9 (3) (1994) 385-393. 
[11] A. Kolonko, C. Madryas, Modernization of underground pipes in towns in Poland, Tunnelling and Underground Space Technology, 11 (2) (1996) 215-220.

[12] L. Legrand, O. Blanpain, F. Buyle-Bodin, Promoting the urban utilities tunnel technique using a decision-making approach, Tunnelling and Underground Space Technology 19 (1) (2004) 79-83.

[13] M. Ghorbani, M. Sharifzadeh, S. Yasrobi, M. Daiyan, Geotechnical, structural and geodetic measurements for conventional tunnelling hazards in urban areas - The case of Niayesh road tunnel project, Tunnelling and Underground Space Technology 31 (1) (2012) 1-8.

[14] C. Madryas, Methods of gathering data for determining the cost of underground infrastructure failure, Tunnelling and Underground Space Technology 3 (3) (1988) 301-303.

[15] J. Curiel-Esparza, J. Canto-Perello, Understanding the major drivers for implementation of municipal sustainable policies in underground space, International Journal of Sustainable Development \& World Ecology 19 (6) (2012) 506-514.

[16] P. Riera, J. Pasqual, The importance of urban underground land value in project evaluation: a case study of Barcelona's utility tunnel, Tunnelling and Underground Space Technology 7 (3) (1992) 243-250.

[17] R. Sterling, J. Carmody, Underground Space Design, Van Nostrand Reinhold, New York, 1993.

[18] R. Sterling, Underground technologies for livable cities, Tunnelling and Underground Space Technology, 12(4) (1997) 479-490.

[19] P. Duffaut, M. Labbe, From underground road traffic to underground city planning, in: Proceedings of the International Conference Urban Underground Space: a Resource for Cities, 2002.

[20] S. Thibault, M. Trépanier, D. Fougères, The urban underground of Montreal: the commission of electrical and public services, Canadian Journal of Urban Research 12 (1) (2003) 77-101.

[21] I.E. Zevgolis, A.A. Mavrikos, D.C. Kaliampakos, Construction, storage capacity and economics of an underground warehousing - Logistics center in Athens, Greece, Tunnelling and Underground Space Technology 19 (2) (2004) 165-173.

[22] I.E. Zevgolis, Building underground: Special techniques for a storage facility, in: Proceedings of the Construction Research Congress: Broadening Perspectives, 2005.

[23] J.H. Wang, A. Koizumi, X. Liu, Advancing sustainable urban development in China, Proceedings of the Institution of Civil Engineers: Municipal Engineer 161 (1) (2008) 3-10.

[24] J.J. Cano-Hurtado, J. Canto-Perello, Sustainable development of urban underground space for utilities, Tunnelling and Underground Space Technology 14(3) (1999) 335340.

[25] J.C. Zhang, X.M. Ding, Y.S. Pang, W.P. Li, H.W. Tong, X.C. Zheng, Y. Xu, Analysis for development and utilization of underground space in Guangzhou. Gongcheng Lixue/Engineering Mechanics 26 (2) (2009) 106-114.

[26] M.S. Ozdemir, T.L. Saaty, The unknown in decision making, what to do about it, European Journal of Operational Research 174 (1) (2006) 349-359.

[27] G.K.L. Lee, E.H.W. Chan, The analytic hierarchy process (AHP) approach for assessment of urban renewal proposals, Social Indicators Research 89 (1) (2008) 155-168. 
[28] Syamsuddin, J. Hwang, The use of AHP in security policy decision making: an open office calc application, Journal of Software 5 (10) (2010) 1162-1169.

[29] R.B. Thapa, Y. Murayama, Drivers of urban growth in the Kathmandu valley, Nepal: examining the efficacy of the analytic hierarchy process, Applied Geography 30 (1) (2010) 70-83.

[30] E.K. Zavadskas, Z. Turskis, J. Tamosaitiene, Selection of construction enterprises management strategy based on SWOT and multi-criteria analysis, Archives of Civil and Mechanical Engineering 11(4) (2011) 1063-1082.

[31] C.C. Hsu, B.A. Sandord, The Delphi technique: making sense of consensus. Practical Assessment, Research and Evaluation 12(10) (2007) 1-7.

[32] Marchais-Roubelat, F. Roubelat, The Delphi method as a ritual: inquiring the Delphi Oracle, Technological Forecasting \& Social Change 78 (9) (2011) 1491-1499.

[33] H.A. Gracht, Consensus measurement in Delphi studies, review and implications for future quality assurance, Technological Forecasting and Social Change 79 (8) (2012) 1525-1536.

[34] D.V.L. Hunt, D. Nash, C.D.F. Rogers C.D.F., Sustainable utility placement via Multi-Utility Tunnels, Tunnelling and Underground Space Technology. (2012) doi:10.1016/j.tust.2012.02.001

[35] Laistner, H. Laistner, Proven sustainability above and below ground, in: Proceedings of the 17th International Conference on Urban Planning and Regional Development in the Information Society, 2012.

[36] J. Canto-Perello, J. Curiel-Esparza, An analysis of utility tunnel viability in urban areas, Civil Engineering and Environmental Systems 23 (1) (2006) 11-19.

[37] B. Gronostajska, The affect of human feelings on creation of housing, Archives of Civil and Mechanical Engineering 8(1) (2008) 107-117.

[38] M. Robati, F. Atabi, Environmental impacts of urban utility tunnel construction case study: Urban utility tunnel district 22 of Tehran, Journal of Environmental Studies 36 (54) (2010) 59-68.

[39] J. Canto-Perello, J. Curiel-Esparza, V. Calvo, Analysing utility tunnels and highway networks coordination dilemma, Tunnelling and Underground Space Technology 24 (2) (2009) 185-189.

[40] D.V.L. Hunt, I. Jefferson, M.R. Gaterell, C.D.F. Rogers, Planning for sustainable utility infrastructure, Proceedings of the Institution of Civil Engineers: Urban Design and Planning 162 (4) (2009) 187-201.

[41] C.D.F. Rogers, T. Hao, S.B. Costello, M.P.N. Burrow, N. Metje, D.N. Chapman, J. Parker, R.J. Armitage, J.H. Anspach, J.M. Muggleton, K.Y. Foo, P. Wang, S.R. Pennock, P.R. Atkins, S.G. Swingler, A.G. Cohn, K. Goddard, P.L. Lewin, G. Orlando, M.A. Redfern, A.C.D. Royal, A.J. Saul, Condition assessment of the surface and buried infrastructure - A proposal for integration, Tunnelling and Underground Space Technology 28 (2012) 202-211.

[42] Y.J. Jung, Evaluation of subsurface utility engineering for highway projects: Benefit-cost analysis, Tunnelling and Underground Space Technology 27 (2012) 111-122.

[43] J. Canto-Perello, J. Curiel-Esparza, Human factors engineering in utility tunnel design, Tunnelling and Underground Space Technology 16 (3) (2001) 211-215.

[44] R. Green, The essential role of governance in project development, Proceedings of the Institution of Civil Engineers-Municipal Engineer 162 (3) (2009), 179-185. 
[45] J. Canto-Perello, J. Curiel Esparza, Assessing governance issues of urban utility tunnels, Tunnelling and Underground Space Technology 33 (2013) 82-87.

[46] J. Canto-Perello, J. Curiel-Esparza, Risks and potential hazards in utility tunnels for urban areas, Proceedings of the Institution of Civil Engineers-Municipal Engineer 156 (1) (2003) 51-56.

[47] J. Curiel-Esparza, J. Canto-Perello, Indoor atmosphere hazard identification in person entry urban utility tunnels, Tunnelling and Underground Space Technology 20(5) (2005) 426-434.

[48] A.O. Abdul Salam, Safety in automated transportation tunnels, in: Proceedings of the 15th Mediterranean Conference on Control and Automation, 2007.

[49] A.-P. Tang, Z.-Q.Li, R.-C. Feng, X.-Y. Zhou, Model experiment and analysis on seismic response of utility tunnel systems using a shaking table, Journal of Harbin Institute of Technology 41 (6) (2009) 1-5.

[50] J. Zhou, Q. Tang, J. Zhang, Dynamic risk assessment for excavation engineering based on human factors, in: 1st International Conference on Information Science and Engineering, ICISE, 2009.

[51] M.M. Fouladgar, A. Yazdani-Chamzini, E.K. Zavadskas, Risk evaluation of tunnelling projects, Archives of Civil and Mechanical Engineering 12(1) (2012) 112.

[52] J.P. Godard, Urban underground space and benefits of going underground, in: World Tunnel Congress of the International Tunnelling Association, 2004.

[53] Z. Ping, C. Zhilong, Y. Hongyu, W. Hui, On utilization of underground space to protect historical relics model, Tunnelling and Underground Space Technology 24 (3) (2009) 245-249.

[54] T.L. Saaty, Decision making with the analytic hierarchy process, International Journal of Services Sciences 1(1) (2008) 83-98.

[55] T.L. Saaty, How to make a decision: the analytic hierarchy process, European Journal of Operational Research 48(1) (1990) 9-26.

[56] T.L. Saaty, The analytic hierarchy process, McGraw-Hill, New York, 1980. 


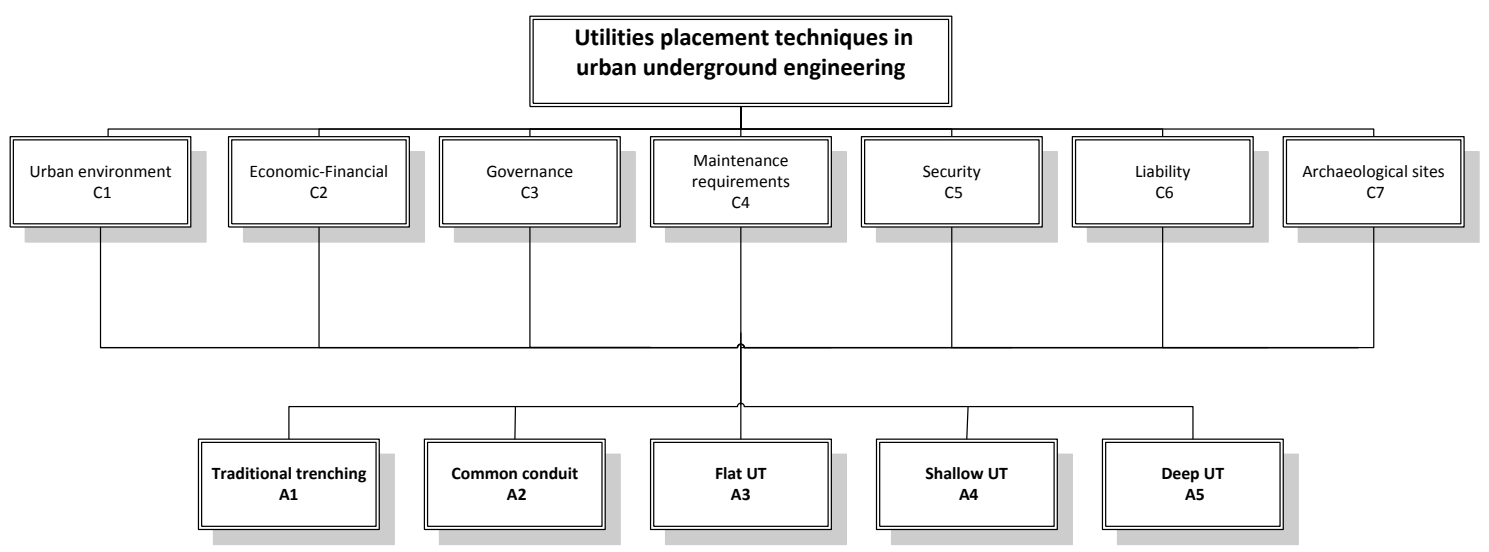

Fig. 1. Hierarchy to determine the technique for utilities placement in urban underground 
Figure 2

\section{ACCEPTED MANUSCRIPT}

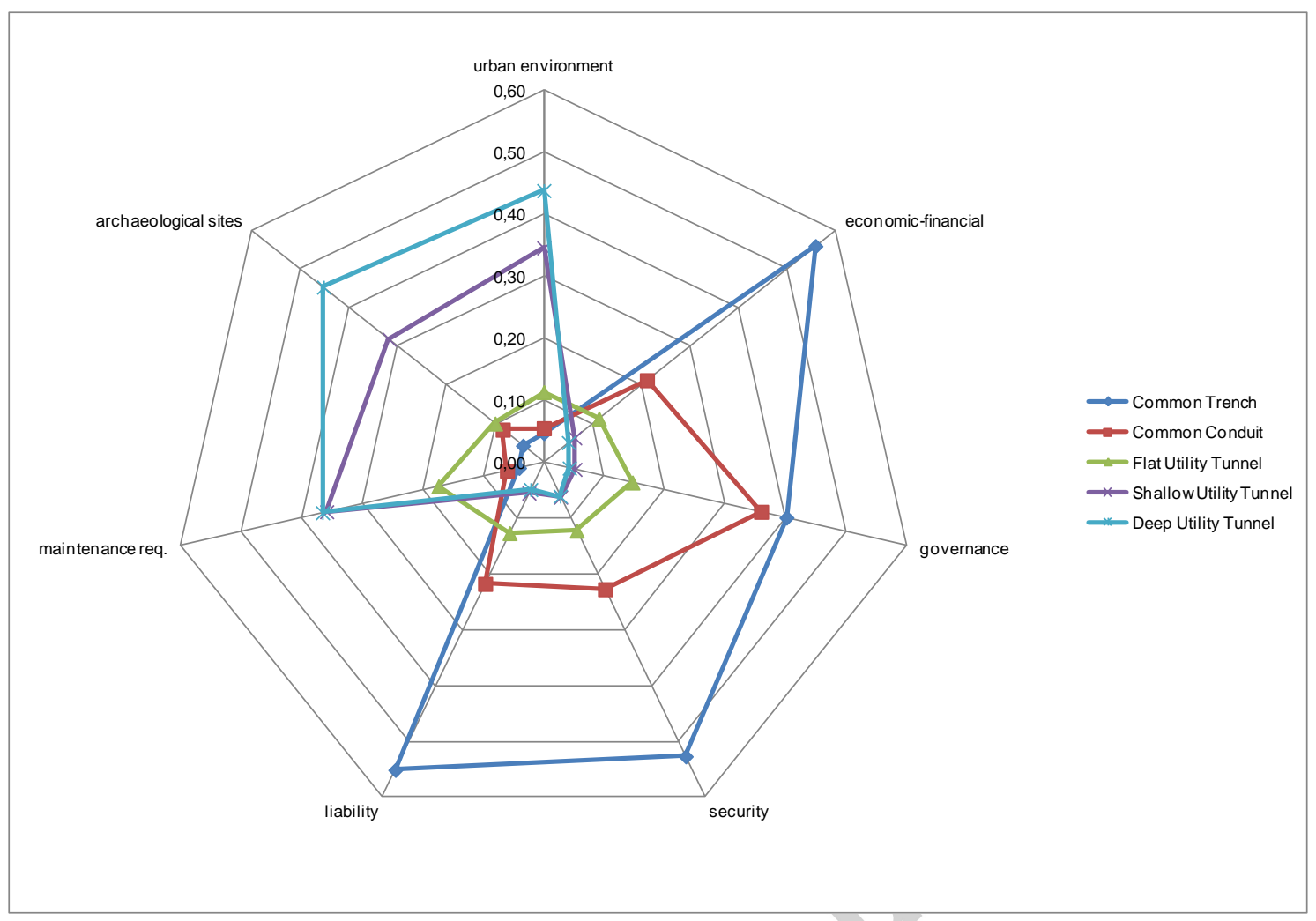

Fig. 2. The weights of each alternative for each criterion. 
Figure 3

\section{ACCEPTED MANUSCRIPT}

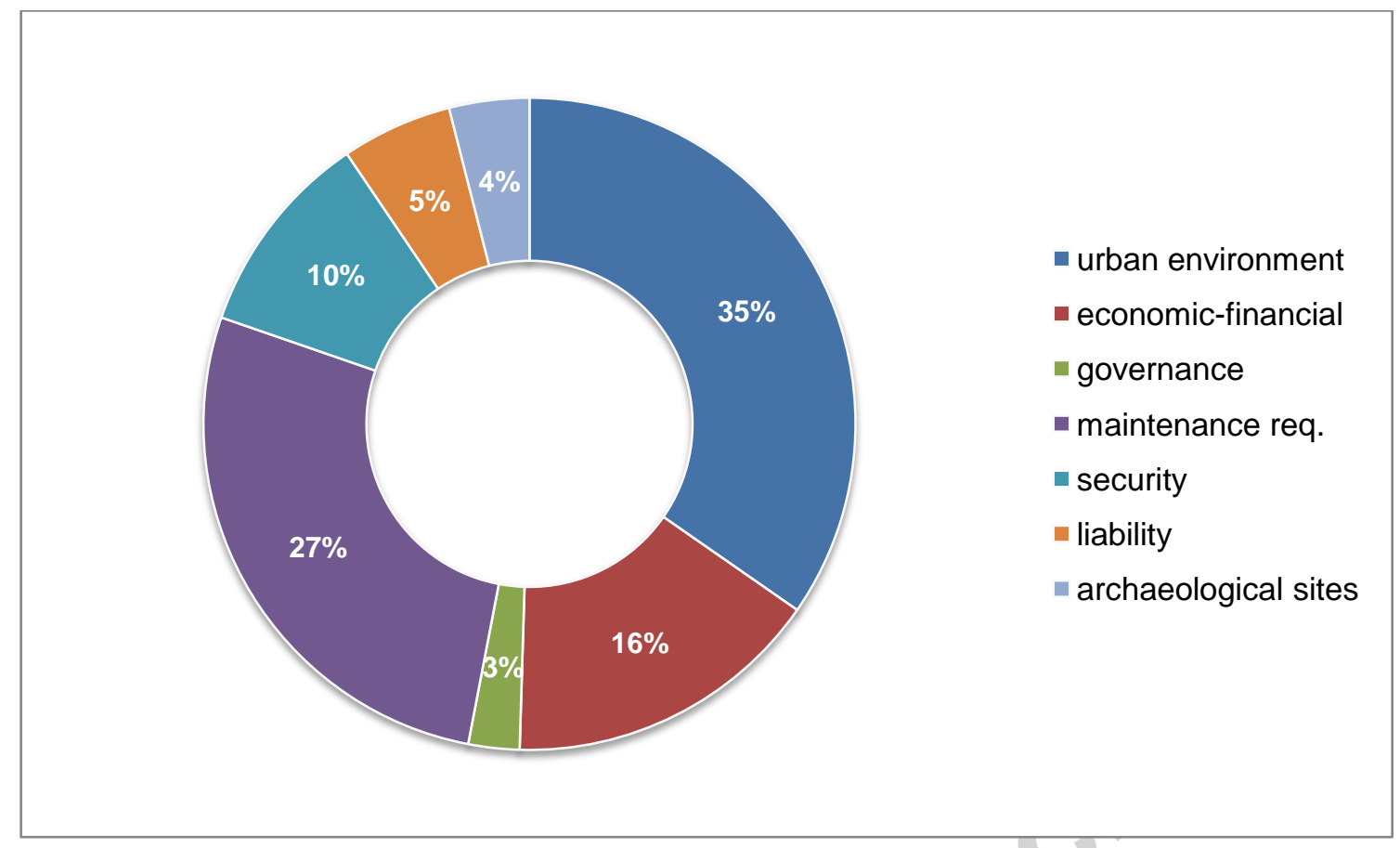

Fig. 3. The weights of each criterion for the overall goal. 
With respect to the overall goal, possible alternatives for utilities placement in urban subsurface

Q1 How important is urban environment (C1) when it is compared to economic-financial (C2)

Q2 How important is urban environment (C1) when it is compared to governance (C3)

Q3 How important is urban environment (C1) when it is compared to maintenance requirements (C4)

Q4 How important is urban environment (C1) when it is compared to security (C5)

Q5 How important is urban environment (C1) when it is compared to liability (C6)

Q6 How important is urban environment (C1) when it is compared to archaeological sites (C7)

Q7 How important is economic-financial (C2) when it is compared to governance (C3)

Q8 How important is economic-financial (C2) when it is compared to maintenance requirements (C4)

Q9 How important is economic-financial (C2) when it is compared to security (C5)

Q10 How important is economic-financial (C2) when it is compared to liability (C6)

Q11 How important is economic-financial (C2) when it is compared to archaeological sites (C7)

Q12 How important is governance (C3) when it is compared to maintenance requirements (C4)

Q13 How important is governance (C3) when it is compared to security (C5)

Q14 How important is governance (C3) when it is compared to liability (C6)

Q15 How important is governance (C3) when it is compared to archaeological sites (C7)

Q16 How important is maintenance requirements (C4) when it is compared to security (C5)

Q17 How important is maintenance requirements (C4) when it is compared to liability (C6)

Q18 How important is maintenance requirements (C4) when it is compared to archaeological sites (C7)

Q19 How important is security (C5) when it is compared to liability (C6)

Q20 How important is security (C5) when it is compared to archaeological sites (C7)

Q21 How important is liability (C6) when it is compared to archaeological sites (C7)

Table 1. Questionnaire to assess main criteria. 


\begin{tabular}{clc}
\hline Notation & \multicolumn{1}{c}{ Meaning } & Intensity of importance \\
\hline EP & A criterion or alternative is extremely preferred to another & 9 \\
VP & A criterion or alternative is very strongly preferred to another & 7 \\
MP & A criterion or alternative is moderately preferred to another & 5 \\
SP & A criterion or alternative is slightly preferred to another & 3 \\
QP & A criterion or alternative is equally preferred to another & 1 \\
SN & A criterion or alternative is slightly non-preferred to another & $1 / 3$ \\
MN & A criterion or alternative is moderately non-preferred to another & $1 / 5$ \\
VN & A criterion or alternative is very strongly non-preferred to another & $1 / 7$ \\
EN & A criterion or alternative is extremely non-preferred to another & $1 / 9$ \\
\hline
\end{tabular}

Table 2. 9-point scale for pairwise comparisons in AHP for evaluation, linguistic terms and their meaning. 


\begin{tabular}{|c|c|c|c|c|c|c|c|c|c|c|}
\hline \multirow[t]{2}{*}{ Pairwise criteria } & \multicolumn{10}{|c|}{ Results for every expert } \\
\hline & 1st & 2nd & 3rd & 4th & 5th & 6th & 7th & 8th & 9th & 10th \\
\hline Urban environment vs. economic-financial & MP & SP & SP & VP & QP & MP & SN & EP & QP & VP \\
\hline Urban environment vs. governance & EP & VP & VP & EP & MP & EP & VP & VP & EP & EP \\
\hline Urban environment vs. maintenance re & $\mathrm{MN}$ & SN & $\mathrm{SP}$ & $\mathrm{SP}$ & QP & VN & MN & SN & SP & QP \\
\hline Urban environment vs. security & EP & MP & SP & MP & VP & $Q P$ & MP & SP & QP & VP \\
\hline Urban environment vs. liability & VP & VP & MP & MP & SP & EP & VP & EP & MP & SP \\
\hline Urban environment vs. archaeologic & MP & EP & VP & VP & SP & QP & VP & VP & $\mathrm{SP}$ & MP \\
\hline Economic-financial vs. governance & VP & EP & EP & EP & MP & VP & EP & EP & MP & EP \\
\hline Economic-financial vs. maintenar & QP & SN & SN & MN & QP & SP & VN & $\mathrm{MN}$ & VN & $\mathrm{MN}$ \\
\hline Economic-financial vs. security & SP & SP & QP & MP & MN & MN & $\mathrm{SP}$ & QP & QP & P \\
\hline Econ & $\mathrm{SP}$ & $\mathrm{SP}$ & MP & QP & MP & MP & SN & QP & MP & MP \\
\hline Econ & MP & MP & MP & QP & SP & SP & MP & MP & QP & MP \\
\hline intenan & $\mathrm{VN}$ & EN & EN & $\mathrm{VN}$ & MN & SN & $\mathrm{VN}$ & EN & EN & EN \\
\hline Governance vs. security & $\mathrm{VN}$ & $\mathrm{VN}$ & MN & $\mathrm{VN}$ & VN & SN & VN & EN & EN & VN \\
\hline Gover & MN & VN & $\mathrm{VN}$ & $\mathrm{VN}$ & QP & SN & $\mathrm{MN}$ & VN & $\mathrm{VN}$ & VN \\
\hline Govern & $\mathrm{SN}$ & QP & QP & SN & SN & SN & QP & QP & SN & SN \\
\hline Maintenance requirements & SP & VP & $\mathrm{SP}$ & MP & MP & SP & $S P$ & MP & $S P$ & SP \\
\hline Maintenance requirements $\mathrm{v}$ & VP & VP & VP & MP & SP & MP & VP & MP & MP & VP \\
\hline Maintenance requirements $\mathbf{v}$ & EP & EP & VP & VP & VP & EP & EP & MP & VP & EP \\
\hline Security vs. liability & QP & QP & QP & $\mathrm{SP}$ & MP & QP & SP & SP & QP & SP \\
\hline Security vs. archaeologi & QP & SP & MP & QP & $\mathrm{VP}$ & MP & MP & MP & QP & MP \\
\hline Liability vs. archaeological sites & $\mathrm{SN}$ & QP & SN & $\mathrm{MN}$ & SP & SP & $\mathrm{MN}$ & QP & QP & SP \\
\hline
\end{tabular}

Table 3. Evaluation results of the main criteria with respect to the overall goal. 


\section{ACCEPTED MANUSCRIPT}

\begin{tabular}{ccccccccc}
\hline & C1 & C2 & C3 & C4 & C5 & C6 & C7 & Priority Vector \\
\hline C1 & 1 & 4.1333 & 7.8000 & 1.2210 & 4.6000 & 6.0000 & 5.4000 & 0.3467 \\
C2 & 0.2419 & 1 & 7.8000 & 0.6552 & 2.0400 & 3.3333 & 3.8000 & 0.1581 \\
C3 & 0.1282 & 0.1282 & 1 & 0.1517 & 0.1613 & 0.2590 & 0.6000 & 0.0253 \\
C4 & 0.8190 & 1.5262 & 6.5900 & 1 & 400000 & 5.8000 & 7.8000 & 0.2728 \\
C5 & 0.2174 & 0.4902 & 6.2008 & 0.2500 & 1 & 2.2000 & 3.8000 & 0.1024 \\
C6 & 0.1667 & 0.3000 & 3.8603 & 0.1724 & 0.4545 & 1 & 1.3067 & 0.0549 \\
C7 & 0.1852 & 0.2632 & 1.6667 & 0.1282 & 0.2632 & 0.7653 & 1 & 0.0397 \\
\hline
\end{tabular}

Table 4. Priority vector and consistency analysis of the pairwise comparison matrix for the seven criteria. 


\section{ACCEPTED MANUSCRIPT}

\begin{tabular}{lcccccccccc} 
Pairwise criteria & \multicolumn{10}{c|}{ Results for every expert } \\
\cline { 2 - 11 } & 1st & 2nd & 3rd & 4th & 5th & 6th & 7th & 8th & 9th & 10th \\
Traditional Trench vs. Common Conduit & QP & SP & SP & MP & MP & QP & SP & MP & SP & SP \\
Traditional Trench vs. Flat UT & SP & MP & MP & MP & VP & MP & MP & MP & VP & SP \\
Traditional Trench vs. Shallow UT & EP & VP & EP & EP & EP & EP & VP & EP & EP & EP \\
Traditional Trench vs. Deep UT & EP & EP & EP & EP & EP & EP & EP & EP & EP & EP \\
Common Conduit vs. Flat UT & SP & QP & QP & SP & SP & QP & QP & QP & SP & QP \\
Common Conduit vs. Shallow UT & MP & SP & SP & SP & MP & MP & SP & MP & SP & SP \\
Common Conduit vs. Deep UT & MP & MP & MP & SP & MP & MP & MP & MP & MP & SP \\
Flat UT vs. Shallow UT & SP & QP & QP & SP & QP & QP & QP & SP & QP & SP \\
Flat UT vs. Deep UT & SP & SP & SP & SP & QP & QP & QP & SP & QP & SP \\
Shallow UT vs. Deep UT & QP & SP & SP & QP & QP & QP & QP & QP & QP & QP \\
\hline
\end{tabular}

Table 5. Evaluation results of the main criteria with respect to the overall goal. 


\section{ACCEPTED MANUSCRIPT}

\begin{tabular}{|c|c|c|c|c|c|c|}
\hline C1 & $\mathrm{A} 1$ & $\mathrm{~A} 2$ & $\mathrm{~A} 3$ & $\mathrm{~A} 4$ & $\mathrm{~A} 5$ & Priority Vector \\
\hline A1 & 1 & 0.7333 & 0.5067 & 0.1270 & 0.1111 & 0.0470 \\
\hline A2 & 1.3636 & 1 & 0.3467 & 0.1644 & 0.1422 & 0.0550 \\
\hline A3 & 1.9737 & 2.8846 & 1 & 0.2800 & 0.2533 & 0.1134 \\
\hline A4 & 7.8750 & 6.0811 & 3.5714 & 1 & 0.6667 & 0.3461 \\
\hline A5 & 9.0000 & 7.0313 & 3.9474 & 1.5000 & 1 & 0.4385 \\
\hline
\end{tabular}

Table 6. Priority vector and consistency analysis of the pairwise comparison matrix for the five alternatives with respect to criterion 1 (C1-Urban environment). 


\section{ACCEPTED MANUSCRIPT}

\begin{tabular}{ccccccc}
\hline C2 & $\mathrm{A} 1$ & $\mathrm{~A} 2$ & $\mathrm{~A} 3$ & $\mathrm{~A} 4$ & $\mathrm{~A} 5$ & Priority Vector \\
\hline A1 & 1 & 3.2000 & 5.0000 & 8.6000 & 9.0000 & $\mathbf{0 . 5 5 9 6}$ \\
A2 & 0.3125 & 1 & 1.8000 & 3.8000 & 4.6000 & $\mathbf{0 . 2 1 2 5}$ \\
A3 & 0.2000 & 0.5556 & 1 & 1.8000 & 2.2000 & $\mathbf{0 . 1 1 3 4}$ \\
A4 & 0.1163 & 0.2632 & 0.5556 & 1 & 1.4000 & $\mathbf{0 . 0 6 3 5}$ \\
A5 & 0.1111 & 0.2174 & 0.4545 & 0.7143 & 1 & $\mathbf{0 . 0 5 1 0}$ \\
\hline \multicolumn{7}{c}{$\lambda_{\max }=5.20$} \\
$\mathrm{Cl}=0,049$ & $\mathrm{CR}=0.0440<0.1$ & OK
\end{tabular}

Table 7. Priority vector and consistency analysis of the pairwise comparison matrix for the five alternatives with respect to criterion 2 (C2-Economic Financial). 


\section{ACCEPTED MANUSCRIPT}

\begin{tabular}{|c|c|c|c|c|c|c|}
\hline C3 & $\mathrm{A} 1$ & $\mathrm{~A} 2$ & $\mathrm{~A} 3$ & $\mathrm{~A} 4$ & $\mathrm{~A} 5$ & Priority Vector \\
\hline A1 & 1 & 1.1867 & 3.2000 & 8.2000 & 7.8000 & 0.4010 \\
\hline A2 & 0.8427 & 1 & 3.3333 & 7.0000 & 6.8000 & 0.3589 \\
\hline A3 & 0.3125 & 0.3000 & 1 & 4.2000 & 3.6000 & 0.1464 \\
\hline A4 & 0.1220 & 0.1429 & 0.2381 & 1 & 1.8000 & 0.0514 \\
\hline A5 & 0.1282 & 0.1471 & 0.2778 & 0.5556 & 1 & 0.0423 \\
\hline
\end{tabular}

Table 8. Priority vector and consistency analysis of the pairwise comparison matrix for the five alternatives with respect to criterion 3 (C3-Governance). 


\section{ACCEPTED MANUSCRIPT}

\begin{tabular}{|c|c|c|c|c|c|c|}
\hline $\mathrm{C4}$ & $\mathrm{A} 1$ & $\mathrm{~A} 2$ & $\mathrm{~A} 3$ & $\mathrm{~A} 4$ & $\mathrm{~A} 5$ & Priority Vector \\
\hline A1 & 1 & 0.6533 & 0.1848 & 0.1295 & 0.1263 & 0.0409 \\
\hline A2 & 1.5306 & 1 & 0.3467 & 0.1714 & 0.1651 & 0.0608 \\
\hline A3 & 5.4124 & 2.8846 & 1 & 0.4267 & 0.4133 & 0.1741 \\
\hline A4 & 7.7206 & 5.8333 & 2.3438 & 1 & 1.0000 & 0.3587 \\
\hline A5 & 7.9146 & 6.0577 & 2.4194 & 1.0000 & 1 & 0.3656 \\
\hline
\end{tabular}

Table 9. Priority vector and consistency analysis of the pairwise comparison matrix for the five alternatives with respect to criterion 4 (C4-Maintenance requirements). 


\section{ACCEPTED MANUSCRIPT}

\begin{tabular}{|c|c|c|c|c|c|c|}
\hline $\mathrm{C5}$ & $\mathrm{A} 1$ & $\mathrm{~A} 2$ & $\mathrm{~A} 3$ & $\mathrm{~A} 4$ & $\mathrm{~A} 5$ & Priority Vector \\
\hline A1 & 1 & 3.2000 & 4.2000 & 7.2000 & 7.2000 & 0.5269 \\
\hline A2 & 0.3125 & 1 & 2.1333 & 4.0000 & 4.0000 & 0.2274 \\
\hline A3 & 0.2381 & 0.4688 & 1 & 2.1333 & 2.1333 & 0.1225 \\
\hline A4 & 0.1389 & 0.2500 & 0.4688 & 1 & 1.0667 & 0.0624 \\
\hline A5 & 0.1389 & 0.2500 & 0.4688 & 0.9375 & 1 & 0.0609 \\
\hline
\end{tabular}

Table 10. Priority vector and consistency analysis of the pairwise comparison matrix for the five alternatives with respect to criterion 5 (C5-Security). 


\section{ACCEPTED MANUSCRIPT}

\begin{tabular}{|c|c|c|c|c|c|c|}
\hline C6 & A1 & A2 & A3 & A4 & A5 & Priority Vector \\
\hline $\mathrm{A1}$ & 1 & 2.8000 & 6.2000 & 7.8000 & 8.8000 & 0.5511 \\
\hline $\mathrm{A} 2$ & 0.3571 & 1 & 2.2000 & 4.0000 & 4.0000 & 0.2179 \\
\hline A3 & 0.1613 & 0.4545 & 1 & 3.0000 & 3.4000 & 0.1269 \\
\hline A4 & 0.1282 & 0.2500 & 0.3333 & 1 & 1.2000 & 0.0552 \\
\hline A5 & 0.1136 & 0.2500 & 0.2941 & 0.8333 & 1 & 0.0489 \\
\hline
\end{tabular}

Table 11. Priority vector and consistency analysis of the pairwise comparison matrix for the five alternatives with respect to criterion 6 (C6-Liability). 


\section{ACCEPTED MANUSCRIPT}

\begin{tabular}{|c|c|c|c|c|c|c|}
\hline C7 & $\mathrm{A} 1$ & $\mathrm{~A} 2$ & A3 & $\mathrm{A} 4$ & A5 & Priority Vector \\
\hline A1 & 1 & 0.5600 & 0.3867 & 0.1238 & 0.1143 & 0.0430 \\
\hline A2 & 1.7857 & 1 & 0.5867 & 0.4400 & 0.1600 & 0.0845 \\
\hline A3 & 2.5862 & 1.7045 & 1 & 0.2438 & 0.1771 & 0.1003 \\
\hline A4 & 8.0769 & 2.2727 & 4.1016 & 1 & 0.8000 & 0.3187 \\
\hline A5 & 8.7500 & 6.2500 & 5.6452 & 1.2500 & 1 & 0.4535 \\
\hline
\end{tabular}

Table 12. Priority vector and consistency analysis of the pairwise comparison matrix for the five alternatives with respect to criterion 7 (C7-Archaeological sites). 


\section{ACCEPTED MANUSCRIPT}

\begin{tabular}{cccccccc}
\hline & C1 & C2 & C3 & C4 & C5 & C6 & C7 \\
\hline A1 & 0.0470 & 0.5596 & 0.4010 & 0.0409 & 0.5269 & 0.5511 & 0.0430 \\
A2 & 0.0550 & 0.2125 & 0.3589 & 0.0608 & 0.2274 & 0.2179 & 0.0845 \\
A3 & 0.1134 & 0.1134 & 0.1464 & 0.1741 & 0.1225 & 0.1269 & 0.1003 \\
A4 & 0.3461 & 0.0635 & 0.0514 & 0.3587 & 0.0624 & 0.0552 & 0.3187 \\
A5 & 0.4385 & 0.0510 & 0.0423 & 0.3656 & 0.0609 & 0.0489 & 0.4535 \\
\hline
\end{tabular}

Table 13. Priority matrix for selecting utilities placement techniques in urban underground. 


\section{ACCEPTED MANUSCRIPT}

\begin{tabular}{lc}
\hline \multicolumn{1}{c}{ Alternative } & Overall priority result \\
\hline A1 - Traditional trenching & 0.2121 \\
A2 - Common conduit & 0.1169 \\
A3 - Flat utility tunnel & 0.1319 \\
A4 - Shallow utility tunnel & 0.2512 \\
A5 - Deep utility tunnel & 0.2878 \\
\hline
\end{tabular}

Table 14. Global priorities for each of the alternatives. 